\title{
Avaliação do efeito do óleo-resina de copaíba (Copaifera sp.) na proliferação celular in vitro
}

\author{
Effect of copaiba oleoresin (Copaifera sp.) on the in vitro cellular proliferation
}

\author{
Edson de Oliveira NOGUEIRA ${ }^{1}$; Adriano Sodré Magalhães NOVAES ${ }^{1}$; Camila Maria Sene SANCHEZ ${ }^{1}$; \\ Cláudio de Moraes ANDRADE ${ }^{1}$; Marta Fernanda Albuquerque da SILVA ${ }^{1}$
}

${ }^{1}$ Instituto de Veterinária da Universidade Federal Rural do Rio de Janeiro, Seropédica - RJ, Brasil

\begin{abstract}
Resumo
O óleo de copaíba é uma resina extraída pela perfuração do tronco de árvores do gênero Copaifera sp., usado como cicatrizante em várias regiões do Brasil. São comprovados seus efeitos antimicrobianos e antiinflamatórios, sem relatos de atividade sobre a proliferação celular. No presente trabalho foi observada a dinâmica da proliferação de células MDBK (Madin Darby Bovine Kidney) mantidas em meio de cultivo adicionado de diferentes concentrações do óleo de copaíba, utilizando-se como controle células mantidas em meio sem adição do oleoresina (grupo M) e células no meio com aplicação do solvente tween 80 , na diluição $10^{-3}$ (grupo MT). Diluições decimais de $10^{-1}$ até $10^{-3}$ mostraram-se tóxicas e, portanto, os estudos de proliferação partiram da diluição $10^{-4}$ até $10^{-7}$. Observou-se que houve crescimento mais acelerado em todos os grupos adicionados do óleo-resina nas primeiras 24 horas, com destaque para a diluição $10^{-5}$, que teve sua taxa de proliferação 5,47 vezes maior que a do grupo M. Concluiu-se que o óleo-resina de copaíba se mostrou estimulante da multiplicação celular, o que pode ser um dos mecanismos de seu efeito positivo sobre a cicatrização, somado àqueles previamente comprovados na literatura.
\end{abstract}

Palavras-chave: Cicatrização de Feridas. Óleo-resina de Copaíba. Proliferação de células.

\begin{abstract}
Copaiba oleoresin is extracted from the trunk of Copaifera sp genus trees and used for treating wounds in several regions of Brazil. Its antimicrobial and anti-inflammatory effects have been proved, however there are no reports of activity on cell growth. Proliferation of MDBK (Madin Darby Bovine Kidney) cells was evaluated under the influence of different concentrations of Copaiba oleoresin. Control groups consisted of cells in medium without addition of oleoresin (M group) and cells in the medium with application of the solvent Tween 80 at dilution $10^{-3}$ (TM group). Decimal dilutions of $10^{-1}$ to $10^{-3}$ were shown to be toxic and, therefore, the proliferation studies were conducted from dilution $10^{-4}$ to $10^{-7}$. Cell growth was faster in all groups that received the Copaiba oleoresin dilutions in the first 24 hours, specially the $10^{-5}$ dilution group, which proliferation rate was 5,47 higher than that of $\mathrm{M}$ group. It was concluded that Copaiba oleoresin stimulates cell multiplication, which may be one mechanism of its positive effect on wound healing, in association with those previously known.
\end{abstract}

Keywords: Wound healing. Copaiba oleoresin. Cell proliferation.

\section{Introdução}

Nos últimos anos, o retorno à terapêutica natural trouxe de volta os fitoterápicos para as farmácias de todo o país, mas o conhecimento de sua utilização e suas aplicações se perderam, ou aparecem bastante confusas nas centenas de publicações que não apresentam mais que duas ou três propriedades farmacológicas já bastante conhecidas ${ }^{1}$. Schenkel, Gosmann e Petrovick ${ }^{2}$ citam a importância histórica do uso de plantas medicinais, relatando que até o século XIX, os recursos terapêuticos eram constituídos predominantemente por plantas e extratos vegetais.

A história do manejo de feridas se confunde com a história da humanidade; o fenômeno da cicatriza-

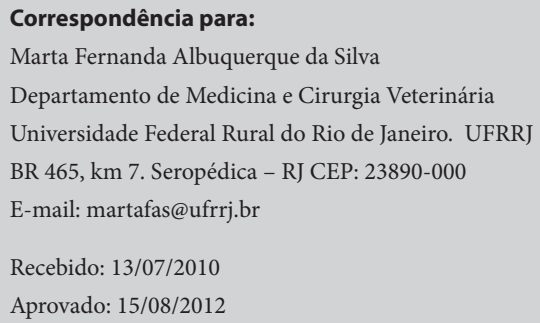


ção tem fascinado o homem e inúmeras alternativas de tratamento tópico de feridas cutâneas têm sido relatadas, utilizando-se substâncias de origem animal, vegetal e mineral, como bile, sangue, frutas, cascas de árvores, alumínio, sais de cobre e até argila³. O uso popular de plantas em cicatrização de feridas é inicialmente relacionado com efeitos adstringentes e antimicrobianos ${ }^{3,4}$. Apesar de muito freqüentes durante vários séculos, estes tratamentos não passavam de tentativas empíricas.

Pesquisas aprofundadas têm demonstrado que a cicatrização é uma resposta biológica complexa que envolve células, produtos celulares e componentes extracelulares que são funcionalmente independentes, mas que agem em conjunto para restaurar a integridade estrutural e funcional dos tecidos lesados 5 . Segundo Fontana ${ }^{6}$, o primeiro estágio do processo de cicatrização compreende a fase inflamatória, caracterizada pela ativação do sistema de coagulação sangüínea e liberação de mediadores e fatores quimiotáxicos. $\mathrm{Na}$ fase proliferativa ocorre a formação de um tecido de granulação altamente vascularizado. Durante a última fase, a reparativa, ocorre a síntese, migração e maturação de fibras colágenas, cicatrizando o tecido lesado.

Entre as plantas usadas, popularmente, em cicatrização de ferimentos cutâneos, a copaíba se apresenta com certo destaque, principalmente nas regiões Norte e Nordeste, mas o uso de seu óleo-resina como cicatrizante já é difundido por todo o país, inclusive com a comercialização em ervanários populares, bem como em farmácias oficialmente regulamentadas ${ }^{7,8,9}$.

As copaibeiras são árvores da família das Leguminosae-Caesalpinoideae, de crescimento lento, alcançam de 25 a 40 metros de altura, podendo viver até 400 anos. O tronco é áspero, de coloração escura, medindo de 0,4 a 4 metros de diâmetro1. O óleo de copaíba, em termos biológicos, é um produto de excreção ou desintoxicação do organismo vegetal, e funciona como defesa da planta contra animais, fungos e bactérias10. O óleo de copaíba - uma resina obtida pela perfuração do tronco de árvores do gênero Copaifera sp., comuns no norte do Brasil - era usado por índios da Amazônia pelos seus supostos benefícios sobre a cicatrização de ferimentos cutâneos8.

A atividade marcante do óleo-resina de copaíba sobre as feridas é uma das propriedades mais frequentemente citadas em estudos etnofarmacológicos, entretanto, os estudos farmacológicos são controversos ${ }^{11}$. Diversos autores tentam elucidar em seus trabalhos a ação do óleo de copaíba ${ }^{8,11,12,13,14,15,16,17,18,19}$. A atuação do óleo de copaíba nos processos de cicatrização é por vezes contraditória e, dentre os que afirmam sua eficiência, poucos aplicam uma metodologia clara o suficiente para poder ser reproduzida. Todavia, os resultados encontrados contradizem o senso comum sendo necessária a realização de estudos que comprovem com mais exatidão a influência do óleo de copaíba no processo cicatricial ${ }^{20}$.

Veiga Junior e Pinto ${ }^{1}$ relatam a ocorrência de variações nos princípios ativos (hidrocarbonetos, álcoois sesquiterpênicos e fenóis) presentes no gênero copaíba; os autores afirmam ainda que tais variações podem ocorrer em função das alterações diurnas, sazonais, de intensidade de luz e nutrientes do solo, e concluem que muitas são as ações já confirmadas relacionadas ao gênero, entretanto, ainda são poucas as pesquisas que conseguem elucidar tais princípios ativos e suas funcionalidades.

Avanços recentes em tecnologia biomolecular e de cultivo celular têm revolucionado as pesquisas fisiológicas e farmacológicas relativas à reparação de feridas. A avaliação da proliferação celular é extremamente relevante nos estudos sobre a cicatrização tecidual, uma vez que a multiplicação de vários tipos celulares (como células epiteliais, fibroblastos, células endoteliais) para preenchimento da área lesada é fundamental para o reparo. As células MDBK (Madin Darby Bovine Kidney) têm sido utilizadas no estudo da ação de diversas substâncias sobre a proliferação celular, inclusive extratos vegetais ${ }^{21,22,23,24}$. 
Devido à complexidade do mecanismo biológico envolvido, estudos sobre a cicatrização requerem modelos experimentais in vivo, bem como in vitro ${ }^{25,26}$. Gottrup, Agren e Karlsmark ${ }^{27}$ afirmam que sistemas in vitro são geralmente rápidos, simples, de custo reduzido e envolvem mínimas considerações éticas ou legais. Além disso, permitem a investigação de vários agentes farmacológicos ou fatores biológicos isolados, sem a inerente heterogeneidade dos modelos in vivo; entretanto, ressaltam a dificuldade em extrapolar os resultados das investigações para uma condição real de um organismo normal. Em razão disso, o teste final de um agente cicatrizante deve ser realizado em animais.

Pesquisas avançam progressivamente a respeito da ação do óleo-resina de copaíba sobre a cicatrização, ratificando a importância deste fitoterápico na medicina popular. Portanto, estudos que levem à elucidação de seus efeitos específicos sobre os diferentes mecanismos do processo de cicatrização justificam-se por dar subsídios para sua aplicação no tratamento de diferentes tipos de feridas.

Este trabalho teve como objetivo avaliar o efeito do óleo de copaíba, em diferentes diluições, sobre células do tipo MDBK (Madin Darby Bovine Kidney) em cultivo de monocamada, quanto à sua capacidade de estimulo à proliferação celular.

\section{Material e Método}

O óleo-resina de copaíba utilizado nesta pesquisa foi obtido na Farmácia Escola da Universidade Federal do Pará, na apresentação farmacêutica de frasco contendo $500 \mathrm{ml}$ de óleo in natura, para uso tópico. As diluições foram realizadas a partir da amostra original, uma alíquota $0,1 \mathrm{ml}$ do óleo foi diluída em 0,1 $\mathrm{ml}$ de Tween 80 acrescido de $0,8 \mathrm{ml}$ de meio MEM/ Glasgow (meio essencial mínimo) formando uma solução inicial na concentração de 1:10 (ou seja, 10-1) do óleo. Em seguida, procedeu-se a diluição decimal sucessiva, pela adição de MEM, obtendo-se diluições crescentes até $10^{-7}$.

Foram utilizadas células dos tipos MDBK (Madin Darby Bovine Kidney), catalogadas pela American Type Culture Collection com o código CCL-22, fornecidas pelo Laboratório de Cultivo Celular do Centro Panamericano de Febre Aftosa (CPFA) e mantidas no Laboratório de Viroses Veterinárias (DESP - IV) da Universidade Federal Rural do Rio de Janeiro. As células foram cultivadas, em MEM, com 10\% de Soro Fetal Bovino (SFB), utilizando-se placas de cultivo de 96 furos e incubadas a $37^{\circ} \mathrm{C}$ em atmosfera de $5 \%$ de $\mathrm{CO}_{2}$, por 72 horas, para a formação da monocamada celular.

Para a avaliação do título de citotoxicidade, após a formação da monocamada celular, o meio de cultivo foi retirado da placa, através de aspiração com pipeta Pasteur e, em seguida, $20 \mu \mathrm{l}$ das soluções do óleo, em suas várias concentrações (de $10^{-1}$ a $10^{-7}$ ), foram adicionados às células, utilizando-se 6 furos da placa para cada diluição. Em cada furo, completou-se o volume com $180 \mu \mathrm{l}$ de MEM/Glasgow isento de SFB. As placas foram repostas em incubação e, durante cinco dias consecutivos, examinadas ao microscópio óptico invertido, quanto à viabilidade das células nas diferentes diluições. Considerou-se como células mortas aquelas que se apresentavam arredondadas e flutuantes, ou seja, não aderidas ao fundo da placa. Os resultados diários de viabilidade celular foram anotados e aplicados ao cálculo do título de citotoxicidade, conforme descrito por Reed e Muench ${ }^{28}$.

$\mathrm{Na}$ avaliação da proliferação celular, utilizou-se uma única garrafa Roux contendo células em estoque foram realizados os procedimentos de "tripsinização e ressuspensão", com volumes maiores de MEM/Glasgow, para a obtenção de três lotes de células, denominados LOTE 1, LOTE 2 e LOTE 3. Realizou- se contagem celular no dia zero com o uso do hemocitômetro (câmara de Newbauer), contando-se os quatro campos da extremidade e o campo central. Com base nos resultados de toxicidade, a multiplicação celular foi 
avaliada utilizando-se apenas as diluições de $10^{-4}$ a 10 7; para isso foram utilizadas quatro placas de 24 furos (com $1 \mathrm{ml}$ por furo) para cada lote, separadamente. Em cada furo, foram colocados $0,9 \mathrm{ml}$ de suspensão celular (em MEM) e foi adicionado $0,1 \mathrm{ml}$ da diluição de $10^{-4}$ do óleo (óleo + tween 80) nos furos A1, B1, C1 e D1, de $10^{-5}$ nos furos A2, B2, C2 e D2, e assim sucessivamente até $10^{-7}$. Nos furos A5, B5, C5 e D5 (chamados de "controle de tween" ou "MT") colocou-se tween 80 na diluição $10^{-3}(0,1 \mathrm{~mL})+\operatorname{MEM}(0,9 \mathrm{~mL})$ e os furos A6, B6, C6 e D6 (chamados de "controle celular" ou "M") receberam apenas $1 \mathrm{~mL}$ de MEM. As doze placas foram mantidas em incubação, e as contagens das células foram realizadas em apenas uma das placas de cada lote, por vez, a cada 24 horas até completarem-se 96 horas, com a utilização do hemocitômetro.

Para a leitura diária da proliferação celular, o meio de cultivo era aspirado da placa para a adição de $1 \mathrm{~mL}$ de tripsina, em cada furo, sobre a camada celular. Após um período de 5 minutos, a tripsina era turbilhonada com auxílio de uma pipeta Pasteur, promovendo-se o descolamento e suspensão das células. Em seguida, as suspensões celulares eram recuperadas em tubos de centrífuga, formando-se um "pool” de cada diluição (furos A, B, C e D) e de cada controle. Os tubos, com $4 \mathrm{~mL}$ cada um, eram centrifugados a $2000 \mathrm{~g} / 30 \mathrm{~min}$. e o líquido sobrenadante, cuidadosamente recolhido e descartado, permanecendo apenas $1 \mathrm{~mL}$ em cada tubo. As células eram ressuspendidas e homogeneizadas para se proceder a contagem em hemocitômetro.

$\mathrm{Na}$ análise dos resultados, considerou-se a média entre os valores obtidos nas contagens de cada lote. As taxas de proliferação celular e o tempo de geração (tempo de dobramento celular) foram calculadas após conversão das médias em valores exponenciais.

\section{Resultados}

Nas condições avaliadas, o óleo-resina de copaíba apresentou atividade citotóxica em concentra- ção igual ou superior a $10^{-3}$, sobre o tipo celular estudado.

Um dos lotes apresentou resultados anômalos nos controles M e MT, além de mostrar valores demasiadamente discrepantes entre as diluições. Portanto, havendo a hipótese de falha na experimentação, este lote não foi incluído na composição da média do número de células obtidos nas contagens de proliferação celular, ficando portanto a análise baseada nos dois lotes restantes.

Os valores médios das contagens diárias do número de células e as taxas de proliferação celular estão relacionados na tabela 1 . Pode-se observar que o crescimento foi progressivo em todos os grupos, até as 72 horas, quando iniciou-se um declínio na contagem, exceto no grupo M (células no meio de cultivo).

A tabela 2 apresenta uma comparação entre as taxas de proliferação dos grupos de células às quais adicionou-se o óleo-resina de copaíba $\left(10^{-4}\right.$ a $\left.10^{-7}\right)$, com as do grupo controle $\mathrm{M}$, nos diferentes tempos de avaliação. Observa-se que houve crescimento mais acelerado em todos os grupos adicionados do óleo-resina nas primeiras 24 horas, com destaque para a diluição $10^{-5}$, que teve sua taxa de proliferação 5,47 vezes maior que a do grupo M. A partir de então, nota-se que o crescimento celular progride, porém em taxas menores em relação ao controle.

A tabela 3 apresenta o tempo de dobramento (ou tempo de geração) celular para cada grupo, nos diversos momentos de avaliação. Da mesma forma que nas análises anteriores, o grupo da diluição $10^{-5}$ teve proliferação acentuadamente mais rápida nas primeiras 24 horas, com tempo de dobramento estimado em 11,7 horas em comparação com as 63,8 horas estimadas para o grupo $\mathrm{M}$.

\section{Discussão}

Para que o processo de reparação de feridas seja efetivo em sua plenitude, um dos eventos de maior 
Tabela 1 - Valores médios das contagens diárias de dois lotes de células MDBK em cultivo de monocamada após adição de óleo-resina de copaíba em quatro diluições, tween 80 a $10^{-3}$ (MT) e somente em meio MEM/Glasgow (M) e valores correspondentes de taxas de proliferação celular

\begin{tabular}{cccccccccc}
\hline $\begin{array}{c}\text { Diluições } \\
\text { do óleo- } \\
\text { resina de } \\
\text { copaíba e }\end{array}$ & \multicolumn{3}{c}{ NÚMERO DE CÉLULAS } & \multicolumn{4}{c}{ TAXA DE PROLIFERAÇÃO } \\
\cline { 2 - 10 } controles & 0 & \multicolumn{3}{c}{ Tempo (em horas) } & \multicolumn{5}{c}{ Tempo (em horas) } \\
\hline $10^{-4}$ & 40 & 98 & 527 & 905 & 426 & 0,0162 & 0,0304 & 0,0098 & $-0,0136$ \\
$10^{-5}$ & 40 & 168 & 467 & 730 & 439 & 0,0260 & 0,0185 & 0,0081 & $-0,0092$ \\
$10^{-6}$ & 40 & 85 & 342 & 417 & 351 & 0,0136 & 0,0252 & 0,0036 & $-0,0031$ \\
$10^{-7}$ & 40 & 72 & 410 & 296 & 288 & 0,0106 & 0,0315 & $-0,0059$ & $-0,0005$ \\
MT & 40 & 62 & 380 & 427 & 406 & 0,0079 & 0,0328 & 0,0021 & $-0,0009$ \\
M & 40 & 52 & 304 & 477 & 629 & 0,0047 & 0,0320 & 0,0082 & 0,0050 \\
\hline
\end{tabular}

Tabela 2 - Relação entre as taxas de proliferação $(\mu)$ dos grupos de células MDBK em cultivo de monocamada às quais adicionou-se o óleo-resina de copaíba $\left(10^{-4}\right.$ a $\left.10^{-7}\right)$ e as do grupo controle $\mathrm{M}$, nos diferentes tempos de avaliação

\begin{tabular}{ccccc}
\hline \multirow{2}{*}{$\begin{array}{c}\text { Diluições do } \\
\text { óleo-resina de } \\
\text { copaíba }\end{array}$} & \multicolumn{4}{c}{ RELAÇÃO $\mu$ grupo diluição / $\mu$ grupo M } \\
\cline { 2 - 5 } & 24 & 48 & 72 & 96 \\
\cline { 2 - 5 } Tempo (em horas) \\
\hline $10^{-4}$ & 3,42 & 0,95 & 1,20 & $-2,72$ \\
$10^{-5}$ & 5,47 & 0,58 & 0,99 & $-1,84$ \\
$10^{-6}$ & 2,87 & 0,79 & 0,44 & $-0,62$ \\
$10^{-7}$ & 2,24 & 0,99 & $-0,72$ & $-0,10$ \\
\hline
\end{tabular}

Tabela 3 - Tempo de dobramento (ou tempo de geração) celular em horas para cada grupo de células MDBK em cultivo de monocamada após adição de óleo-resina de copaíba em quatro diluições, tween 80 a $10^{-3}$ (MT) e somente em meio MEM/Glasgow (M), nos diversos momentos de avaliação

\begin{tabular}{ccccc}
\hline \multirow{2}{*}{$\begin{array}{c}\text { Diluições do } \\
\text { óleo-resina } \\
\text { de copaíba e }\end{array}$} & \multicolumn{4}{c}{ TEMPO DE GERAÇÃO } \\
\cline { 2 - 5 } controles & \multicolumn{4}{c}{ Tempo (em horas) } \\
\cline { 2 - 5 } & 24 & 48 & 72 & 96 \\
\hline $10^{-4}$ & 18,7 & 10,0 & 30,7 & $-22,2$ \\
$10^{-5}$ & 11,7 & 16,4 & 37,1 & $-32,9$ \\
$10^{-6}$ & 22,2 & 12,0 & 83,7 & $-97,2$ \\
$10^{-7}$ & 28,5 & 9,6 & $-50,9$ & $-611,2$ \\
MT & 38,2 & 9,2 & 142,3 & $-332,1$ \\
M & 63,8 & 9,5 & 36,8 & 60,5 \\
\hline
\end{tabular}

relevância é a proliferação celular, principalmente em lesões com grandes perdas teciduais. Diversos tipos celulares têm importância para o processo, de acordo com a fase da cicatrização em questão $0^{6}$. Neste contexto, insere-se a avaliação dos efeitos de várias substâncias sobre células em cultivo, método que vem sendo utilizado recentemente por diversos autores ${ }^{25,27,29,30}$.

Optou-se no presente estudo pela utilização do sistema in vitro, pois, como afirmam Gottrup, Agren e Karlsmark ${ }^{27}$ estes testes são geralmente rápidos, simples, de custo reduzido e envolvem mínimas considerações éticas ou legais, sem a inerente heterogeneidade dos modelos in vivo. Este modelo possibilitou avaliar o efeito do óleo-resina de copaíba, especificamente, sobre a multiplicação celular. As células MDBK foram também usadas em outras pesquisas relacionadas à proliferação celular sob influência de diversas substâncias, inclusive extratos vegetais s1,22,23,24 $^{\text {. }}$

Nos estudos da ação de extratos vegetais sobre a proliferação celular in vitro, é comum que as soluções mais concentradas apresentem efeito citotóxico conforme observado por Phan, Rughes e Cherry ${ }^{4}$, na avaliação do extrato de Chromolaena odorata (eupolin). O teste preliminar de citotoxicidade foi aplicado no presente estudo, utilizando-se método tradicional (cálculo de Reed e Muench), que define a concentração letal para $50 \%$ das células cultivadas e forneceu a concentração considerada limite, a partir da qual iniciou-se o estudo da proliferação celular.

O grupo "controle celular" (M) apresentou crescimento gradativo e constante do número de células até 
96 horas, enquanto, nos grupos de células que tiveram seu crescimento acelerado pela ação das diluições do óleo-resina a $10^{-4}$ e $10^{-5}$, houve drástica diminuição da população celular a partir das 72 horas, devido ao rápido consumo de substratos com consequente falta de nutrientes.

Os resultados obtidos no presente trabalho demonstram uma clara influência positiva do óleo-resina de copaíba sobre a proliferação celular, principalmente quando utilizou-se as diluições de 10-5 e 10-4. Outros efeitos do óleo de copaíba relevantes na evolução das feridas vem sendo amplamente estudados, como sua atividade antiinflamatória ${ }^{14,17,18,31,32,33,34,35,36 \text {, }}$ ação contra vários microorganismos, destacando-se o Staphylococcus aureus ${ }^{37,38,39,40,41,42}$, e atividade antioxidante ${ }^{43}$. Por si só, estes efeitos justificam a ampla utilização deste produto na medicina tradicional de comunidades do Norte e Nordeste do país e sua difusão por outras regiões ${ }^{7,8,9}$. Estudos sobre atividade do óleo em proliferação de células não foram encontrados na literatura e os achados do presente trabalho indicam mais um tipo de atuação positiva do óleo de copaíba sobre a cicatrização.

Os achados desta pesquisa divergem da afirmação de Cavalcanti et al. ${ }^{18}$, de que o óleo de copaíba não possui fatores capazes de estimular a proliferação celular e que seu efeito positivo sobre a cicatrização deve-se à sua ação antiinflamatória. Os resultados aqui apresentados demonstram que o óleo de copaíba, em

\section{Referências}

1. VEIGA JUNIOR, V.; PINTO, A. C. O Gênero Copaifera L. Química Nova, v. 25, n. 2, p. 273, 2002.

2.SCHENKEL, E. P; GOSMANN, G.; PETROVICK, P. R. Produtos de origem vegetal e o desenvolvimento de medicamentos. In: SIMÕES, C. M. O.; SCHENKEL, E. P.; GOSMANN, G.; MELLO, J. C. P.; MENTZ, L. A.; PETROVICK, P. R. Farmacognosia - da planta ao medicamento. Porto Alegre: Ed. UFRGS, 2000. p. 291-322.

3. FORREST, R. D. Early history of wound treatment. Journal of the Royal Society of Medicine, v. 75, n. 3, p. 198-205, 1982.

4. PHAN, T. T.; HUGHES, M. A.; CHERRY, G. W. Enhanced proliferation of fibroblasts and endothelial cells treated with an extract of the leaves of Chromolaena odorata (eupolin), an determinadas concentrações, possui efeito proliferativo, devendo-se considerar também suas já comprovadas ações antimicrobiana e antioxidante, características essas que são importantes, alem da ação antiinflamatória, para o processo cicatricial.

Podemos sugerir, com base neste estudo, que ainda há um amplo caminho a ser percorrido pelas pesquisas quanto à atividade do óleo de copaíba sobre a cicatrização de feridas. Outros trabalhos devem ser realizados, usando modelos in vitro que permitam avaliar não apenas a multiplicação celular, mas também a possibilidade de ação sobre a neovascularização, sobre a migração celular, a contração, bem como o estímulo à produção de colágeno, conforme vem sendo descrito na literatura sobre outros produtos vegetais ${ }^{26,44,45,46}$. Além disso, delineamentos experimentais visando comparar os efeitos de diferentes espécies de Copaifera, ou ainda, as resinas de uma mesma espécie coletadas de ambientes diversificados e estabelecendo as composições químicas de cada uma, podem trazer resultados interessantes que levem à determinação de substâncias orgânicas específicas com atividade em uma ou outra fase da cicatrização.

\section{Conclusões}

O óleo de copaíba exerceu ação positiva sobre a proliferação de células, in vitro, empregadas neste estudo, havendo uma relação entre concentração e efeito.

herbal remedy for treating wounds. Plastic and Reconstructive Surgery, v. 101, n. 3, p. 756-765, 1998.

5. BHALLA, D. K. Evaluation of wound repair mechanisms with an in vitro cell culture model. Journal of Laboratory and Clinical Medicine, v. 134, n. 4, p. 331-332, 1999.

6. FONTANA, C. Fisiologia da cicatrização de feridas. Patologia Clínica, v. 1, n. 1, p. 1-22, 1996.

7. PIO CORRÊA, M. Dicionário das plantas úteis do Brasil, e das exóticas cultivadas. Rio de Janeiro: Imprensa Nacional, 1984. p. 370-375.

8. BRITO, N. M. B. Aspectos morfológicos e morfométricos da cicatrização de feridas cutâneas abertas em ratos tratados 
com óleo de copaíba. 1986. 58 f. Dissertação (Mestrado em Técnica Operatória e Cirurgia Experimental) - Escola Paulista de Medicina, Universidade Federal de São Paulo, São Paulo, 1986.

9. GRAMOSA, N. V. Estudo químico-farmacológico de Copaifera langsdorffii Desf. 2001. 269 f. Tese (Doutorado em Química Orgânica) - Escola de Engenharia Química, Universidade Federal do Ceará, Fortaleza, 2001.

10.PONTES, A. B.; CORREIA, D. Z.; COUTINHO, M. S.; MOTHÉ C. G. Emulsão dermatológica a base de copaíba. Revista Analytica, v. 7, p. 36-42, 2003.

11.LEANDRO, L. M.; VARGAS, F. S.; BARBOSA, P. C. S.; NEVES J. K. O.; SILVA, J. A.; VEIGA-JUNIOR, V. F. Chemistry and biological activities of terpenoids from copaiba (Copaifera spp.) oleoresins. Molecules, v.17, n. 4, p. 3866-3889, 2012. doi:10.3390/molecules17043866.

12.EURIDES, D.; MAZZANTI, A.; GONCALVES, G. F.; BELLETI, M. E.; SILVA, L. A. F.; FIORAVANTI, M. C. S.; CHAVES, N. S. T.; BOMBONATO, P. P.; CAMPOS, V. A.; OGATA, A. $\mathrm{S}$. Aspectos morfológicos, morfométricos e histológicos da reparação tecidual de feridas abertas de camundongos tratadas com óleo de copaíba (Copaifera langsdorffii). Veterinária Notícias, v. 4, n. 1, p. 77-82, 1998.

13.PAIVA, L. A. F.; RAO, V. S. N.; GRAMOSA, N. V.; SILVEIRA, E. R. Gastroprotective effect of Copaifera langsdorffii oleoresin on experimental gastric ulcer models in rats. Journal of Ethnopharmacology, v. 62, n. 1, p. 73-78, 1998.

14.BASILE, A. C.; SERTIE, J. A. A.; FREITAS, P. C. D.; ZANINI, A. C. Anti-inflammatory activity of oleoresin from brazilian Copaifera. Journal of Ethnopharmacology, v. 22, n. 1, p. 10109, 1988.

15.PAIVA, L. A. F. Estudo da atividade antiulcerogênica do óleo-resina da Copaifera langsdorffii Desf. 1999. 124 f. Dissertação (Mestrado em Farmacologia) - Escola de Farmácia, Universidade Federal do Ceará, Fortaleza. 1999.

16.PAIVA, L. A. F.; CUNHA, K. M. A.; SANTOS, F. A.; GRAMOSA, N. V.; SILVEIRA, E. R.; RAO, V. S. N. Investigation on the wound healing activity of oleo-resin from Copaifera langsdorffii in rats. Phytotherapy Research, v. 16, n. 8, p. 737739,2002

17.CARVALHO, J. C.; CASCON, V.; POSSEBON, L. S.; MORIMOTO, M. S.; CARDOSO, L. G.; KAPLAN, M. A.; GILBERT, B. Topical anti-inflammatory and analgesic activities of Copaifera duckei Dwyer. Phytotherapy Research, v. 19, n. 11, p. 946-950, 2005.

18.CAVALCANTI NETO, A. T.; ARRUDA, T. E. P.; ARRUDA, T. T. P.; PEREIRA, S. L. S.; TURATTI, E. Análise comparativa entre e óleo-resina de copaíba e o digluconato de clorexidina no processo de cicatrizacão tecidual. Estudo histológico em dorso de ratos. Revista de Odontologia da UNESP, v. 34, n. 2, p. 107-112, 2005.

19.SILVA, J. J. L.; GUIMARAES, S. B.; SILVEIRA, E. R.; VASCONCELOS, P. R.; LIMA, G. G.; TORRES, S. M.; VASCONCELOS, R. C. Effects of Copaifera langsdorffii Desf. on ischemia-reperfusion of randomized skin flaps in rats. Aesthetic Plastic Surgery, v. 33, n. 1, p. 104-109, 2009.

20.MONTES, L. V.; BROSEGHINI, L. P.; ANDREATTA, F. S.; SANT'ANNA, M. E. S.; NEVES, V. M.; SILVA, A. G. Evidências para o uso da óleo-resina de copaíba na cicatrização de ferida - uma revisão sistemática. Natureza On Line, v. 7, n. 2, p 6167, 2009

21.PIHIE, A. H.; STANSLAS, J.; DIN, L. B. Non-steroid receptormediated antiproliferative activity of styrylpyrone derivative in human breast cancer cell lines. Anticancer Research, v. 18, n. 3a, p. 1739-1743, 1998.

22.COULOMBE, R. A.; DREW, G. L.; STERMITZ, F. R. Pyrrolizidine alkaloids crosslink DNA with actin. Toxicology and Applied Pharmacology, v. 154, n. 2, p. 198-202, 1999.

23. KIM, H. Y.; STERMITZ, F. R.; LI, J. K.; COULOMBE, R. A. Comparative DNA cross-linking by activated pyrrolizidine alkaloids. Food and Chemical Toxicology, v. 37, n. 6, p. 619 $625,1999$.

24.LEE, K. H.; KIM, J. H.; LIM, D. S.; KIM, C. H. Anti-leukaemic and anti-mutagenic effects of di(2-ethylhexyl)phthalate isolated from Aloe vera L. Journal Pharmacy Pharmacology, v. 52 , n. 5 , p. $593-598,2000$.

25.CALDERON, M.; LAWRENCE, W. T.; BANES, A. J. Increased proliferation in keloid fibroblasts wounded in vitro. Journal of Surgical Research, v. 61, n. 2, p. 343-347, 1996.

26. PHAN, T. T.; LEE, S. T.; CHAN, S. Y.; HUGHES, M. A.; CHERRY, G. W. Investigating plant-based medicines for wound healing with use of cell culture technologies and in vitro models: a review. Annals Academy of Medicine Singapore, v. 29 , n. 1 , p. $27-36,2000$

27.GOTTRUP, F.; AGREN, M. S.; KARLSMARK, T. Models for use in wound healing research: A survey focusing on in vitro and in vivo adult soft tissue. Wound Repair Regen, v. 8, n. 2, p. 83-96, 2000.

28. REED, L. J.; MUENCH, H. Simple method of estimating 50 per cent end points. American Journal of Hygiene, v. 27, n. 3, p. 493-497, 1938

29.LIMA, S. R. M. Efeitos da óleo-resina de copaíba sobre células de melanoma murino in vivo e in vitro. 1999. $94 \mathrm{f}$ Dissertacão (Mestrado em Ciências Biológicas) - Universidade Federal do Rio de Janeiro, Rio de Janeiro, 1999.

30. COSTA-LOTUFO, L.; CUNHA, G.; FARIAS, P; VIANA, G.; CUNHA, K.; PESSOA, C.; MORAES, M.; SILVEIRA, E.; GRAMOSA, N.; RAO, V. The cytotoxic and embriotoxic effects of kaurenoic acid, a diterpene isolated from Coapifera langsdorffii oleo-resin. Toxicon, v. 40, n. 8, p. 1231, 2002.

31.VEIGA JUNIOR, V. F.; ZUNINO, L.; CALIXTO, J. B. PATITUCCI, M. L.; PINTO, A. C. Phytochemical and antioedematogenic studies of commercial copaiba oils available in Brazil. Phytotherapy Research, v. 15, n. 6, p. 476480,2001

32.BAYLAC, S.; RACINE, P. Inhibition of 5-lipoxygenase by essential oils and other natural fragrant extracts. International Journal Aromatherapy, v. 13, n. 2/3, p. 138-142, 2003.

33.BAYLAC, S.; RACINE, P. Inhibition of human leukocyte elastase by natural fragrant extracts of aromatic plants. International Journal Aromatherapy, v. 14 , n. 4, p. 179-182, 2004.

34.VEIGA JUNIOR, V. F.; ZUNINO, L.; PATITUCCI, M. L.; PINTO, A. C.; CALIXTO, J. B. The inhibition of paw oedema formation caused by the oil of Copaifera multijuga Hayne and its fractions. Journal of Pharmacy and Pharmacology, v. 58, n. 10, p. 1405-1410, 2006.

35.VEIGA JUNIOR, V. F.; ROSAS, E. C.; CARVALHO, M. V.; HENRIQUES, M. G.; PINTO, A. C. Chemical composition and anti-inflammatory activity of copaiba oils from Copaifera cearensis Huber ex Ducke, Copaifera reticulata Ducke and Copaifera multijuga Hayne-A comparative study. Journal of Ethnopharmacology, v. 112, n. 2, p. 248-254, 2007.

36. GOMES, N. M.; REZENDE, C. M.; FONTES, S. P.; MATHEUS, M. E.; PINTO, A. C.; FERNANDES, P. D. Characterization of the antinociceptive and anti-inflammatory activities of fractions obtained from Copaifera multijuga Hayne. Journal 
of Ethnopharmacology, v. 128, n. 1, p. 177-183, 2010.

37.PACHECO, T. A. R. C.; BARATA, L. E. S.; DUARTE, M. C. T. Antimicrobial activity of copaiba (Copaifera spp.) balsams. Revista Brasileira de Plantas Medicinais, v. 8, p. 123-124, 2006. N. Especial.

38. OLIVEIRA, D. F; PEREIRA, A. C.; FIGUEIREDO, H. C.; CARVALHO, D. A.; SILVA, G.; NUNES, A. S.; ALVES, D. S.; CARVALHO, H. W. Antibacterial activity of plant extracts from Brazilian southeast region. Fitoterapia, v. 78, n. 2, p. 142$145,2007$.

39.CORREIA, A. F.; SEGOVIA, J. F.; GONCALVES, M. C.; OLIVEIRA, V. L.; SILVEIRA, D.; CARVALHO, J. C.; KANZAKI, L. I. Amazonian plant crude extract screening for activity against multidrug-resistant bacteria. The European Review for Medical and Pharmacological Sciences, v. 12, n. 6, p. 369-380, 2008.

40.SANTOS, A. O.; UEDA-NAKAMURA, T.; DIAS FILHO, B. P.; VEIGA JUNIOR, V. F.; PINTO, A. C.; NAKAMURA, C. V. Antimicrobial activity of Brazilian copaiba oils obtained from different species of the Copaifera genus. Memórias do Instituto Oswaldo Cruz, v. 103, n. 3, p. 277-281, 2008.

41. MENDONÇA, D. E.; ONOFRE, S. B. Atividade antimicrobiana do óleo-resina produzido pela copaiba - Copaifera multijuga Hayne (Leguminosae). Revista Brasileira de Farmacognosia, v. 19, n. 2b, p. 577-581, 2009.
42.PIERI, F. A.; SILVA, V. O.; SOUZA, C. F.; COSTA, J. C. M.; SANTOS, L. F.; MOREIRA, M. A. S. Antimicrobial profile screening of two oils of copaifera genus. Arquivo Brasileiro de Medicina Veterinária e Zootecnia, v. 64, n. 1, p. 241-244, 2012.

43. MACIEL, H. P. F; GOUVÊA, C. M. C. P.; TOYAMA, M.; SMOLKA, M.; MARANGONI, S.; PASTORE, G. M. Extraction, purification and biochemical characterization of a peroxidase from Copaifera langsdorffii leaves. Quimica Nova, v. 30, n. 5, p. 1067-1071, 2007.

44.SHUKLA, A.; RASIK, A. M.; JAIN, G. K.; SHANKAR, R.; KULSHRESTHA, D. K; DHAWAN, B. N. In vitro and in vivo wound healing activity of asiaticoside isolated from Centella asiatica. Journal of Ethnopharmacology, v. 65, n. 1, p. 1-11, 1999.

45.FRONZA, M.; HEINZMANN, B.; HAMBUGER, M.; LAUFER, S.; MERFORT, I. Determination of the wound healing effect of Calendula extracts using the scratch assay with 3T3 fibroblasts. Journal of Ethnopharmacology, v. 126, n. 3, p. 463-467, 2009

46. SCHMIDT, C.; FRONZA, M.; GOETTERT, M.; GELLER, F.; LUIK. S.; FLORES, E. M.; BITTENCOURT, C. F.; ZANETTI, G. D.; HEINZMANN, B. M.; LAUFER, S.; MERFORT, I. Biological studies on Brazilian plants used in wound healing. Journal of Ethnopharmacology, v. 122, n. 3, p. 523-532, 2009. 